\title{
Breast Adenoma
}

National Cancer Institute

\section{Source}

National Cancer Institute. Breast Adenoma. NCI Thesaurus. Code C40382.

A benign, well circumscribed neoplasm that arises from the breast. Representative examples include apocrine adenoma, tubular adenoma, and pleomorphic adenoma. 